https://doi.org/10.18485/kud_kiaz.2019.ch32

\author{
Зарифа Али-заде \\ Университета г. Нови Сад (Сербия)
}

\title{
НЕКОТОРЫЕ АСПЕКТЫ ВЛИЯНИЯ ВОСТОЧНОЙ МУЗЫКИ (МУГАМА- МАКАМА) НА НАРОДНОЕ ТВОРЧЕСТВО СЕРБИИ И БОСНИИ И ГЕРЦЕГОВИНЫ
}

\begin{abstract}
SUMMARY
Studying the cultural life of Serbia and Bosnia and Herzegovina, everyone can see the influence of Ottoman Culture in this region. During the fifth centuries of Ottoman rule in Balkan region, the Turks spent a big part of their time in the cities, and their culture influenced on the formation of local characteristics of cultural and household traditions. Eastern influence is visible on national dresses, especially in the cities, as well as in the style of songs and dances, where the oriental melismatics shows itself in the usage of melodies.
\end{abstract}

Key words: Serbia and Bosnia and Herzegovina, the Balkans, East Melismatics, culture.

Музыкальная культура народов бывшей Югославии, как и культура в целом, развивалась в сложных исторических условиях разобщённости, порабощения и многовековой борьбы за национальную независимость. Многонациональный состав населения, различные вероисповедания (православие, католицизм, протестантизм, ислам), культурно-исторические и территориальные связи с соседними народами, процесс этнической ассимиляции населения Балканского полуострова способствовали 
возникновению здесь феномена многообразия национальных музыкальных диалектов. При общих для музыкального фольклора всего региона славянских основ, в народной музыке Словении и частично Хорватии обнаруживается близость к немецко-австрийскому народному творчеству, итальянской песне (Адриатическое побережье), венгерской крестьянской песне (северо-восточная Хорватия и область Воеводины в Сербии); в фольклоре Боснии и Герцеговины, Македонии, южной Сербии ощутимо воздействие восточной музыкальной культуры. При этом, разумеется, на формирование как культуры в целом, так и музыкальной культуры этого региона известное воздействие оказали и античная, и византийская культуры.

Сербия находится в юго-восточной Европе, в центральной части Балканского полуострова. В течение истории сербский народ создал несколько государств, а 1389 года по 1872 год Сербия находилась под властью Османской империи. Северные районы современной Сербии с конца семнадцатого века входили в состав Австрийской Империи.

Босния и Герцеговина - государство, расположенное в Юго-Восточной Европе, в западной части Балканского полуострова. Боснийское государство возникло в XIXII-ом веках. Население исповедовало католицизм, православие, часть населения относилась к группе адептов Боснийской церкви. В 1463 году страна подпадает под власть османов и значительная часть населения со временем обращается в ислам.

Балканы - это смесь религий и языков. При этом, однако, здесь можно увидеть общие культурные особенности. Прежде всего, Балканы - это содружество людей с общим менталитетом. Более того, если бы представители всех балканских народов собрались на одной общей свадьбе, то там пили бы одни и те же напитки, играли бы в одни и те же игры, наконец, пели бы одни и те же песни. Таким образом, можно сказать, что на Балканах налицо многокультурная зрелость и общее культурное наследие. 
Выше мы уже отметили, что при изучении культурной жизни Сербии и Боснии и Герцеговины можно увидеть влияние восточной культуры, что вполне естественно, если учесть длительность османского правления в данном регионе. Можно сказать, что воздействию восточной - османской культуры и турецкого языка подверглись практически все балканские языки и народы. Исследования показали, к примеру, что в сербско-хорватском языке некогда имелось около семи тысяч слов турецко-османского происхождения. Однако, что вполне естественно, в процессе изменений языка, как живого организма, число турецко-османских слов, используемых как в повседневной речи, так и в литературе, сократилось примерно до двух тысяч.

Слова турецко-османского происхождения, не утратившие актуальности, используются в самых различных сферах - в общественной, в кулинарной, в бытовой, в музыкальной, в топонимике, во флористике, и, наконец, в повседневной речи. Что же касается музыкальных терминов, то мы можем привести следующие примеры: баглама (bağlama), чалгия (çalg1), чифтетелия (çiftetelli-çifte telli tambur), чемане (kemençe), даире (daire), давулбаш (davul), деф (def), гайде (gayda, tulum), канун (kanun), кавал (kaval), саз (saz), шаргия (şark1-tambur), тамбура (tambur), зурна/зурла (zurna).

Живя в течение многих столетий в пределах Османской Империи, народы Сербии и Боснии и Герцеговины позаимствовали у османов инструменты и музыкальные жанры. Особенно явственно это влияние ощущалось в населенных пунктах и районах с преимущественно мусульманским населением.

Гайде считается старейшим инструментом на Балканах. Инструмент этот похож на тулум, издревле используемый в восточной части черноморского побережья Малой Азии. Впрочем, в данном случае, разумеется, определенно говорить о заимствовании балканскими народами у 
османов этого инструмента, представляющего собой разновидность волынки, известной во многих регионах Европы, не приходится.

Из группы струнных смычковых на Балканах распространен инструмент gusle. Малоазийский (анатолийский) аналог этого инструмента - kemençе, имеющая две формы, одна из которых, причерноморская, наиболее близка к gusle.

В девятнадцатом веке в музыку балканского региона (кроме Хорватии) вошли ансамбли духовых инструментов военно-музыкальных оркестров западного и османского (восточного) происхождения.

Кроме того, среди используемых в этом регионе музыкальных инструментов османского (восточного) происхождения можно отметить следующие - Кавал или Фрула, Зурна - группа духовых инструментов; барабан (давул).

На развитие музыкального фольклора южносербского региона повлияло и разделение между городом и деревней. Население патриархальной сельской общины жило изолированно. При таких обстоятельствах можно было сохранить характер старой сербской музыкальной традиции (обрядовые песни с простой, монотонной ритмическо-мелодической структурой, с элементарным содержанием). Города же стояли на торговых путях, что неизбежно приводило к культурной ассимиляции городского населения. При этом отметим, что основная масса мусульманского населения Балкан, за исключением некоторых районов, жила в городской местности, результатом чего, среди прочего, стало значительное влияние османской (восточной) культуры на формирование локальных особенностей культурно-бытовых традиций балканских народов. Атмосфера повседневной народной жизни данного периода отражается в народных песнях и танцах. Восточные влияния заметны в народных костюмах, особенно в городских, а также в стиле танца, в мелодиях которых заметна ориентальная мелизматика. В языке песен 
юга Сербии и Боснии, каковой регион характеризуется наличием целого ряда диалектов, встречается немало чисто восточных междометий и восклицаний, пришедших сюда через посредство османов - оф, аман, джан'м...

Городские песни южных регионов Сербии более широкого амбитуса, с развитыми богатыми мелодиями и ритмом, часто содержат мелизмы и увеличенную секунду. Большое количество песен этого региона принадлежит гипомиксолидийскому ладу и балканскому минору, но встречаются и модальные ряды как принципы лада. Балканский минор - это лад с большой секстой и хроматически увеличенной четвертой ступенью.

Весьма важным компонентом, характерным для песен данного региона, является ритм. Многие мелодии основаны на метроритме, так называемом народном ритме, который основывается на неравномерной ритмической пульсации. Отличительными характеристиками ритма являются восьмые или шестнадцатые ноты, в группах по три и по две. Известный музыкальный теоретик Зора Василевич отмечает, что «характерными отличиями ритма являются неравномерные пульсации, ритмы Востока и, в некоторой степени, и нашей национальной музыки; не отношения длины, которые характеризуют европейские ритмы, но отношения акцентов, в то время как длительность отступает на второй план». В процессе интерпретации этого ритма Зора Василевич ввела термин мета. Данный термин используется в качестве контраста префиксу изо в противовес традиционным европейским ритмам, где акценту подчиняется продолжительность.

И хотя народная музыка сербов в основном не базируется на модусы-макамы, в ней все же заметно влияние восточной музыки. В основном это чувствуется в музыке городской среды юга Сербии, регионов Вранья и Косово. Это региональная музыка, в которой ощутимо влияние таких макамов, как хиджаз, нихавенти и раст, в которых используются двойные интервалы, триоли и вибрато, и 
богатая ритмическая структура отражает элементы восточной, в данном случае, персидской музыки $(2 / 4,4 / 4,5 / 8,7 / 8$, 9/8). Для такой музыки присуще использование ряда вышеуказанных инструментов - саза, багламы, барабана (давула), зурлы (или зурны). Эту музыку без особого преувеличения можно назвать мостом, соединяющим Восток и Запад.

Традиция городской музыки в Сербии представляет собой, если так можно выразиться, музыкальное направление, в той или иной степени характеризующееся влиянием и Запада, и Востока. Например, в то время как старые городские сербские песни (так называемые «староградские песни»), испытавшие на себе воздействие австрийской музыкальной культуры, носят, в значительной степени, европейский характер, в городских песнях юга Сербии и боснийских мусульман, в так называемых «Севдалинках», чувствуется влияние османской музыки, в частности, в том, что касается модуса.

«Севдалинка» - это название, производное от слова «севда», перешедшего из арабского языка в турецкий, и уже из турецкого языка - в боснийский. Означает это слово «влюбленность», «любовь», и используется как в своей оригинальной форме - «севда», так и в несколько трансформированном виде - «севдах».

«Севдалинка», представляющая собой наиболее распространенную поэтическую форму боснийской лирической анонимной литературы, появилась и развилась в результате культурных изменений, происходивших после перехода боснийцев в ислам. Точная дата появления этой поэтической формы неизвестна, ибо речь идет об анонимных песнях, однако считается, что первые образцы «севдалинок» появились в боснийской культуре в шестнадцатом веке.

Известный исполнитель этого жанра и композитор Омер Побрич полагал, что путь развития «севдалинки» выглядел следующим образом: эзан (призыв к молитве) - илахия (исламские песнопения) - касида/касиде (ближневосточная поэтическая форма, появившаяся еще в доисламский период) - севдалинка. 
Академик, этномузыковед Владо Милошевич указывает на следующие музыкальные элементы, свойственные «севдалинке»: 1) увеличенная секунда; 2) миксолидийский лад, мажор и гармонический минор, который заканчивается на второй ступени; 3) алитерация; 4) фразы на глубоком вдохе и большом диапазоне.

Имеются образцы «севдалинок», исполняемых вне зависимости от религиозной и этнической принадлежности певцов. К примеру, во многих районах бывшей Югославии довольно популярна «севдалинка» «В Стамбуле на Босфоре» (U Stambolu na Bosforu ), в которой поется об умирающем паше (нотный пример 1)

«Севдалинка», представляющая собой яркий образец национальной боснийской музыки, вот уже пять с лишним веков исполняется не только в Боснии и Герцеговине, но и в других частях бывшей Югославии - в Сербии, в Македонии, в Косово, в Черногории. В Сербии «севдалинка» в основном популярна в районах, расположенных на юго-западе страны, то есть в местах компактного проживания боснийцев, в частности, в Санджаке. В качестве примера можно привести «севдалинки» «Хаджина Фата» и «Леле кад пойдо», написанные Реджепом Меджедовичем из города Нови-Пазар, административного центра района Санджак.

Песня «Хаджина Фата» (нотный пример 2) написана в одночастной форме, мелодия начинается в макаме $p a c m$, потом переходит в макам баяты. Песня «Леле кад пойдо» (нотный пример 3) также написана в одночастной форме и опять же начинается в макаме $p a c m$, в дальнейшем переходя в макам басит сузинак.

Пользующаяся большой популярностью народная песня « Айде Яно кучу да не дамо» написана в макаме буселик (нотный пример 4).

Песня „Какве сам куће направио, моја Рамизе“ написана в макаме хиджаз (нотный пример 5) 
Инструментальная пьеса „Ружичасто“ исполняется в макаме раст (нотный пример 6).

«Косовска народна песма» написана в макаме ушак (нотный пример 7).

Сегодня трудно с большой точностью сказать, как именно «севдалинка» исполнялись несколько столетий назад. Единственно известно, что песни эти исполнялись под аккомпанемент саза или шаргии (муз. инструмент, похожий на саз). Солист играл доминирующую роль, имело место большое количество мелизмов и носовых призвуков, и, как правило, было много импровизации.

В конце хотелось бы сказать несколько слов и о такой форме балканской музыки, так «туркия» (или «Румелийские туркия», называемые так вследствие популярности этих песен в европейской части Турции, так называемой «Румелии» - то есть в Восточной Фракии). Румелийские «туркие» в наше время довольно популярны в Турции. Один из примеров румелийской «туркии» в макаме хиджаз - «Вардарска долина» (нотный пример 8).

В данной статье мы не станем подробно рассматривать этот жанр турецкого народного творчества вследствие ограничений, касающихся объема статьи, но я хотела бы подчеркнуть, что если политические границы между балканскими странами существовали и существуют, то культурные границы давно уже преодолены, и точки соприкосновения балканских народов имеются во многих сферах, и музыка - один из самых ярких примеров этих точек соприкосновения.

Studying the cultural life of Serbia and Bosnia and Herzegovina, everyone can see the influence of Ottoman Culture in this region. During the fifth centuries of Ottoman rule in Balkan region, the Turks spent a big part of their time in the cities, and their culture influenced on the formation of local characteristics of cultural and household traditions. Eastern influence is visible on national dresses, especially in the cities, as well as in the style of songs and dances, where the oriental melismatics shows itself in the usage of melodies. 


\section{ЛИТЕРАТУРА}

Васиљевић 3. Теорија ритма, Београд, Универзитет уметности у Београду, 1999.

Vlado Milošević, Sevdalinka, Banja Luka, 1964

Стојановић, С. М. Записи народних мелодија. Београд: Музиколошки институт. 1966.

Cvjetko Rihtman: Orijentalni uticaji u tradicionalnoj muzici Bosne i Hercegovine. Narodno stvaralaštvo - Folklor, 1982.

Semir Vranić, Omer Pobrić, (priređivači). 2005. Sevdah i sevdalinka: Izbor tekstova na devet svjetskih jezika. Visoko: Institut sevdaha - Fondacija Omera Pobrića

From proceedings of scientific Simposium ( 7-9 March, 2018) on the subject of "Mugham science in Azerbaijan: realities and perspectives". 


\section{НОТНЫЙ ПРИМЕР 1}

SEVDALINKA

U STAMBOLU NA BOSFORU
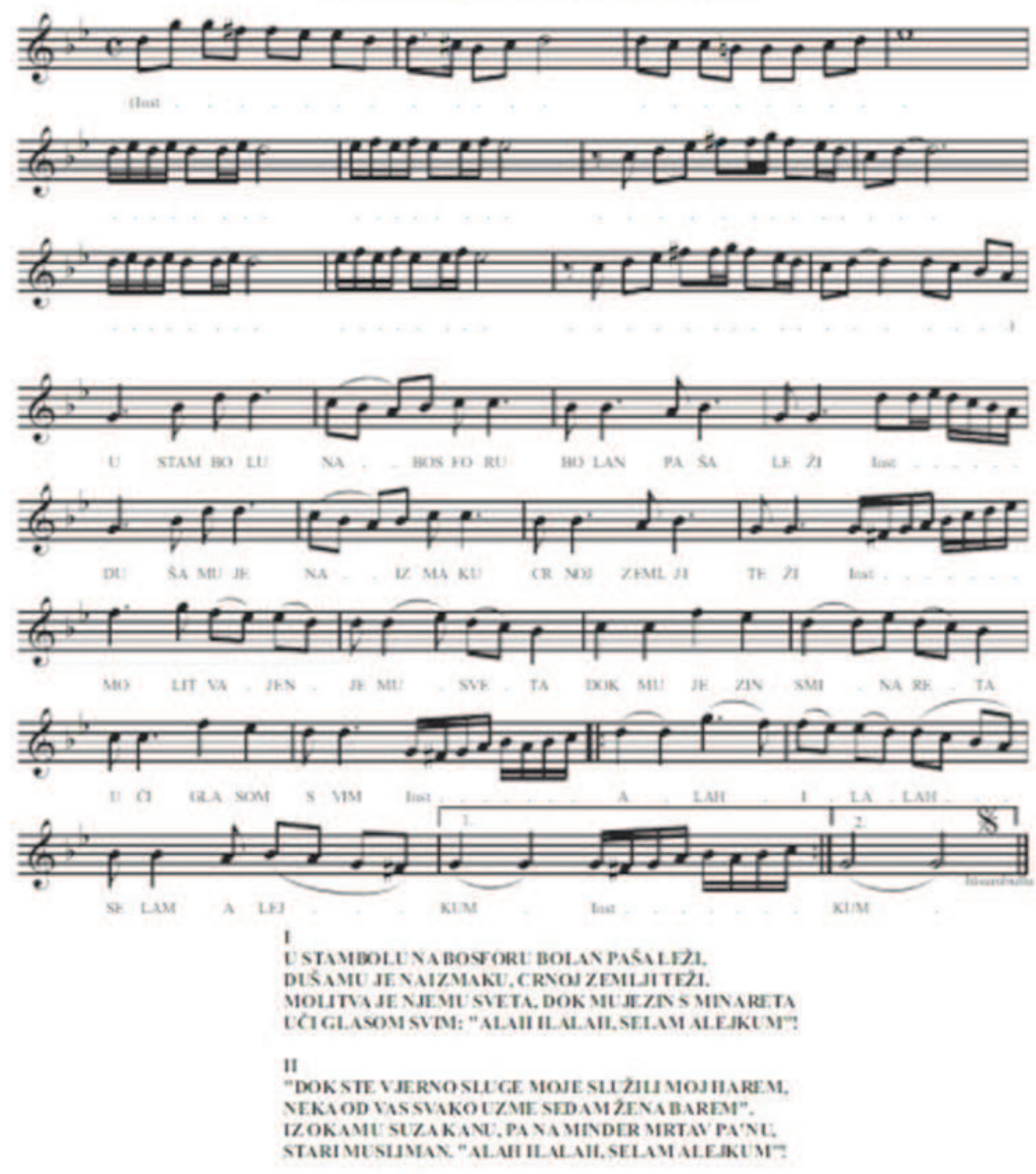


\title{
НОТНЫЙ ПРИМЕР 2
}

\section{HADŽINA FATA}

\author{
OULAST MOVIRALU.

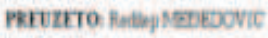
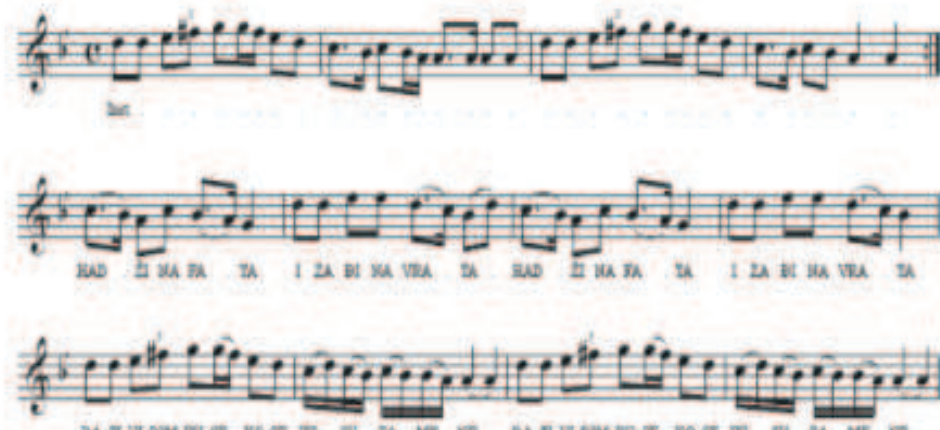

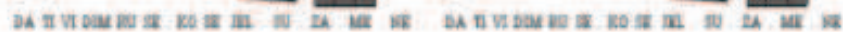
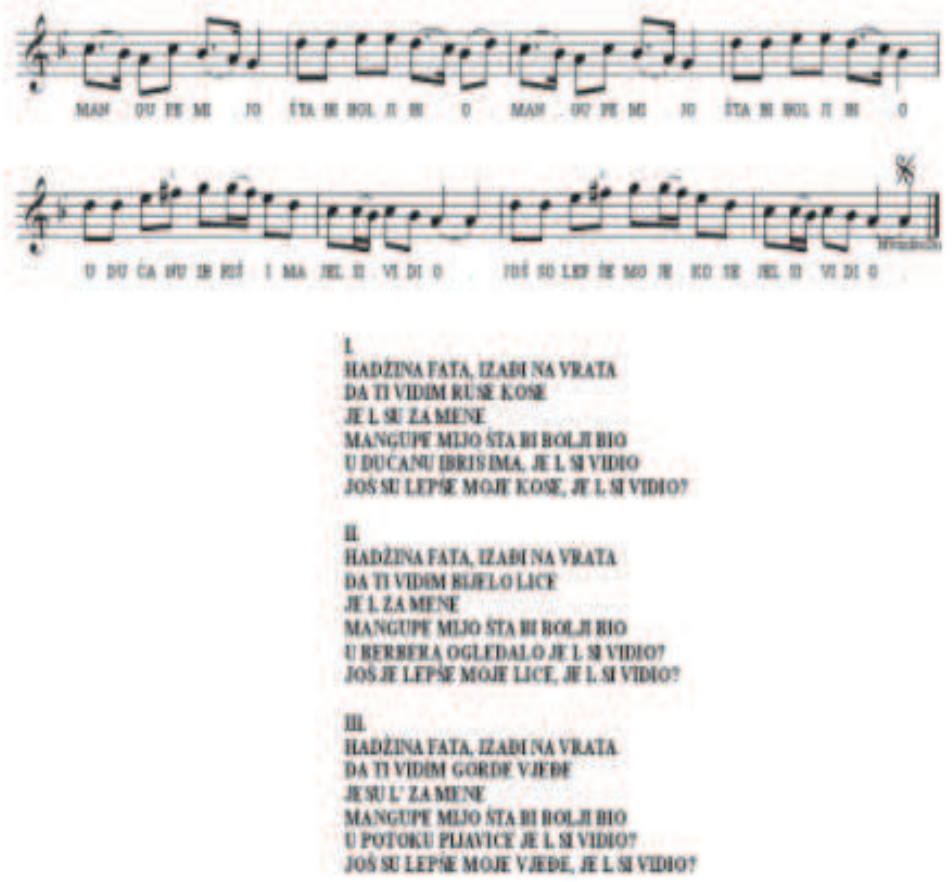


\section{НОТНЫЙ ПРИМЕР 3}

\section{LELE KAD POJDO}

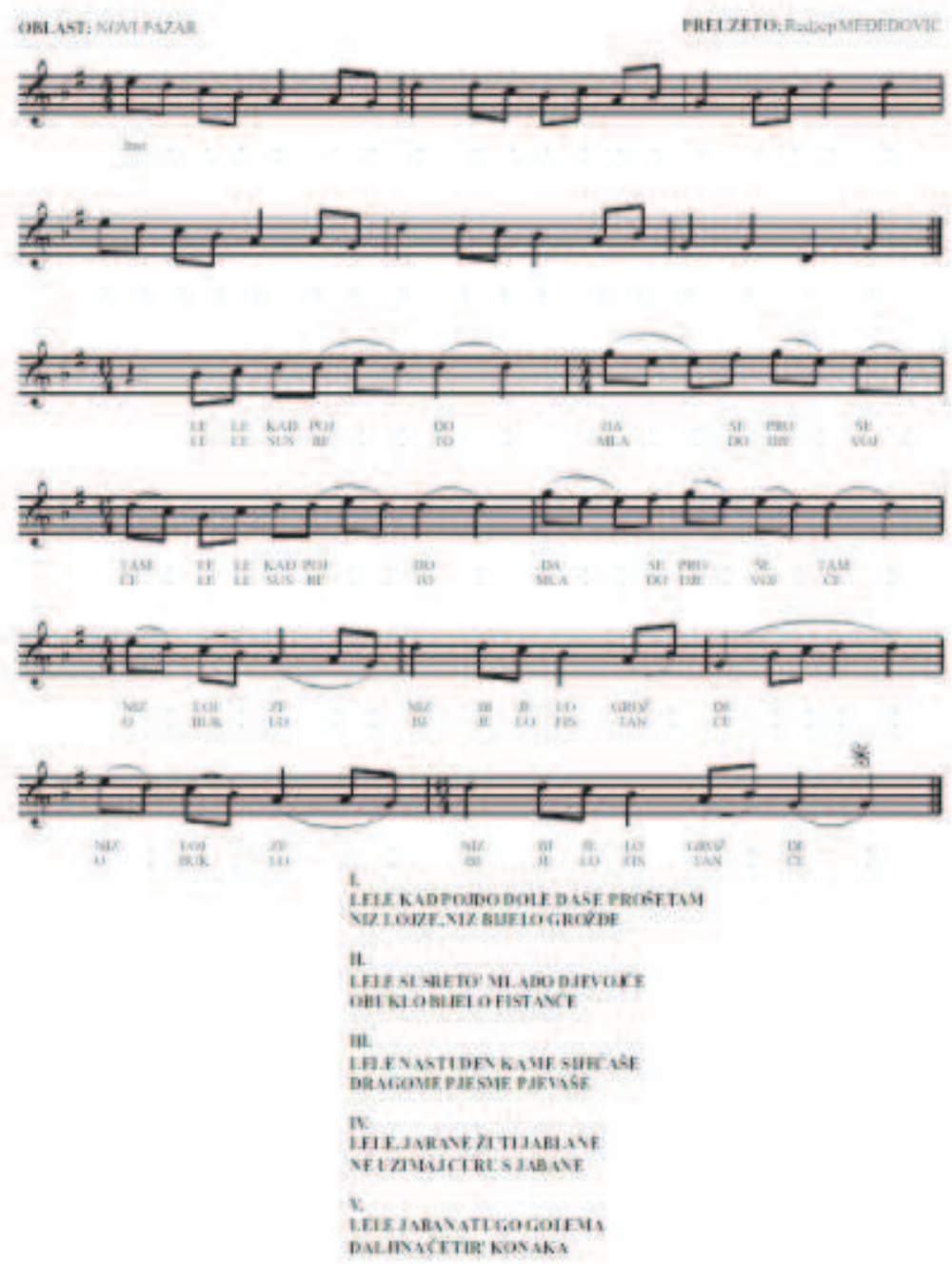




\section{НОТНЫЙ ПРИМЕР 4}

\section{AJDE JANO, KUĆU DA NE DAMO}
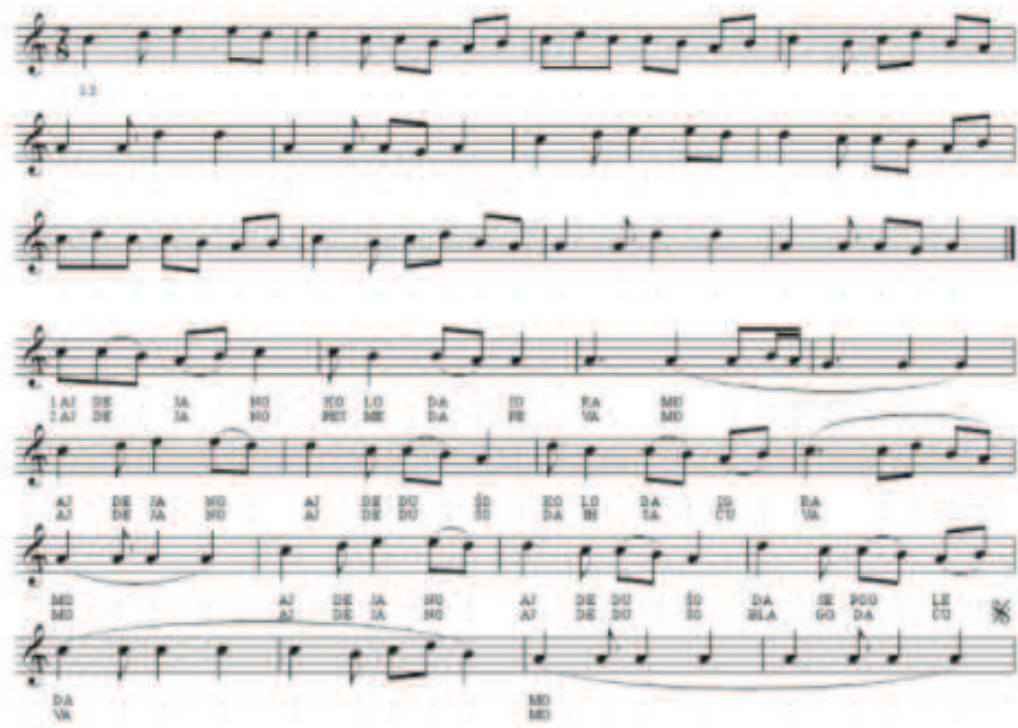

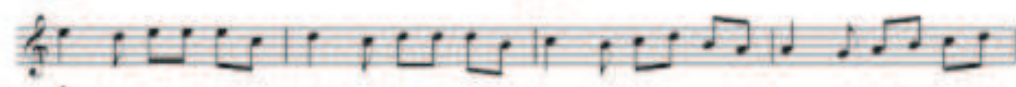

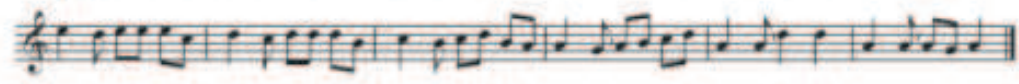

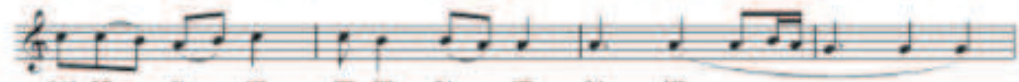

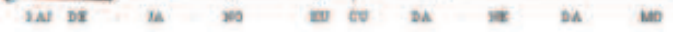

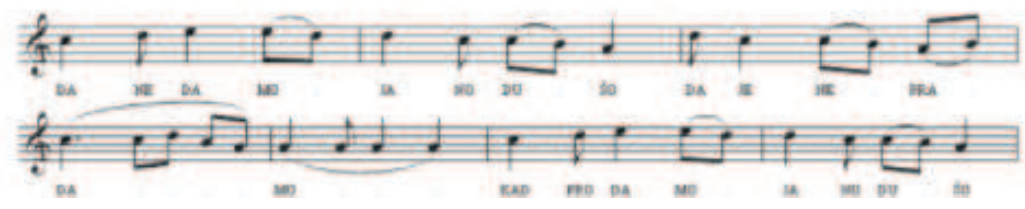




\section{НОТНЫЙ ПРИМЕР 5}

16:50. $107 \mathrm{~h}$

$0 \mathrm{anc}+\mathrm{sen}$ KAKVE SAM KUĆE NAPRAVIO

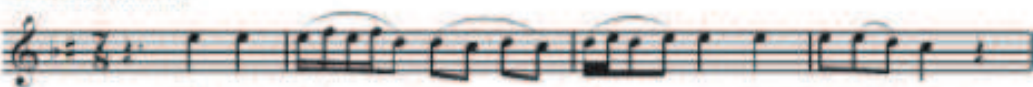

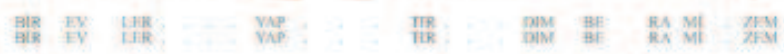
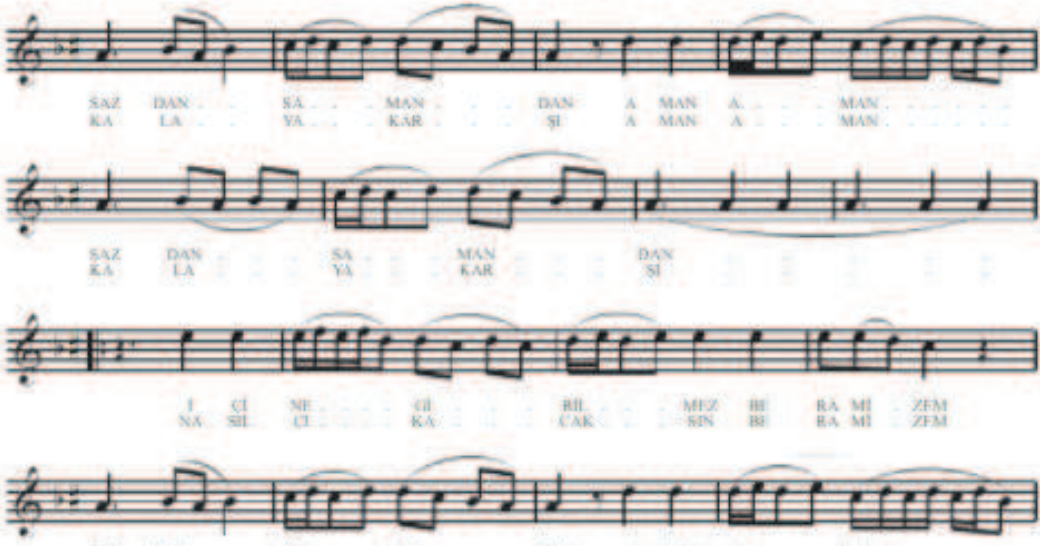

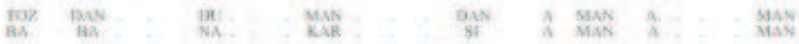

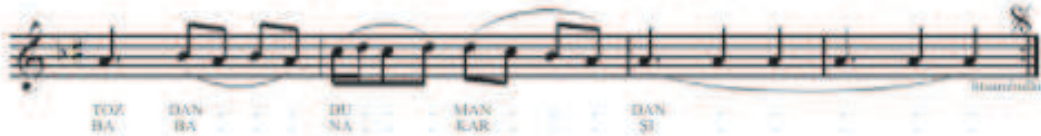

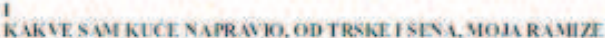

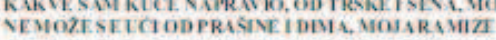

II

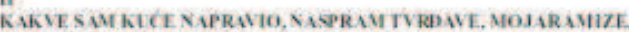

KМKOCESIZMIPREDOCA, MEMRIMIZ 
НОТНЫЙ ПРИМЕР 6

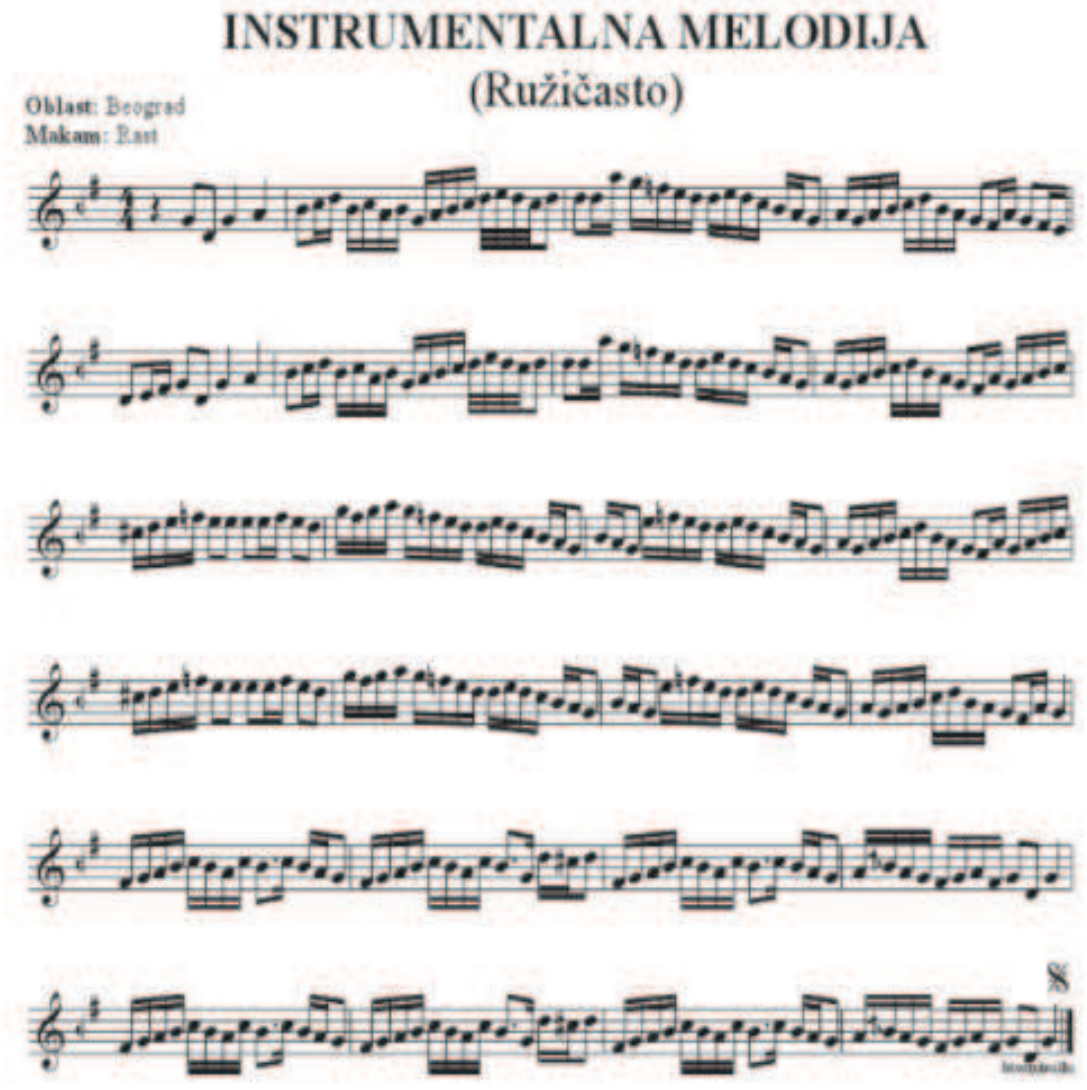




\section{НОТНЫЙ ПРИМЕР 7}

KOSOVSKA NARODNA PESMA

(GUSTA MI MAGLA PADNALA)

oik ase koseswsk.
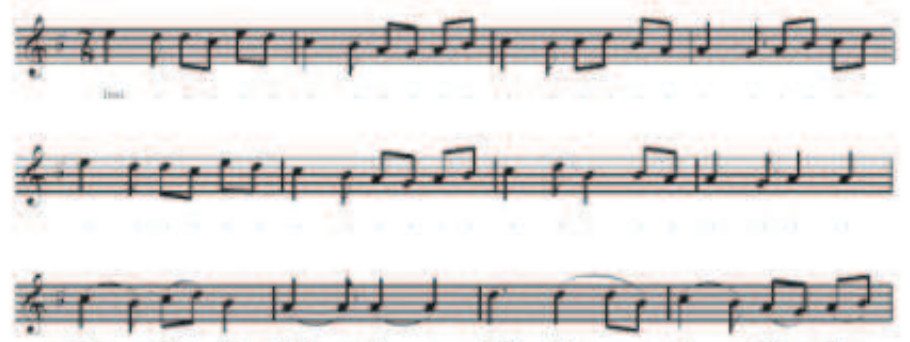

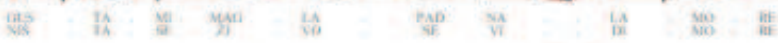

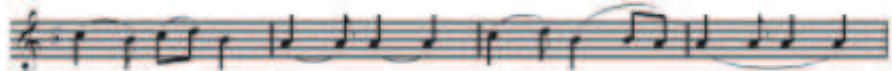

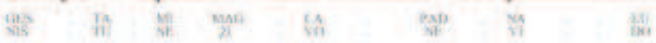

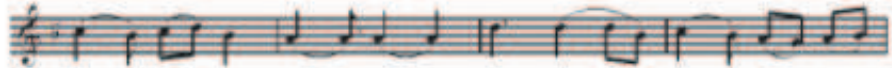

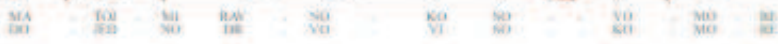

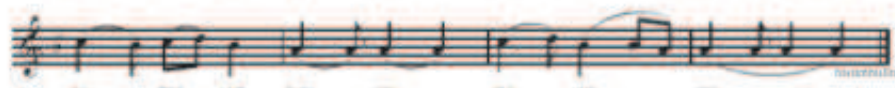

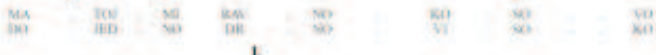

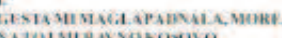

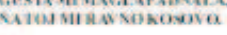

II.

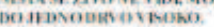

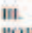

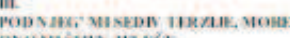

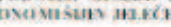

nis

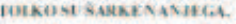




\section{НОТНЫЙ ПРИМЕР 8}

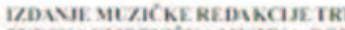

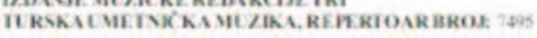

RUMELIJSKA TURKIJA

U MAKAMU HIDŽAZ

(VARDARSKA DOLINA)
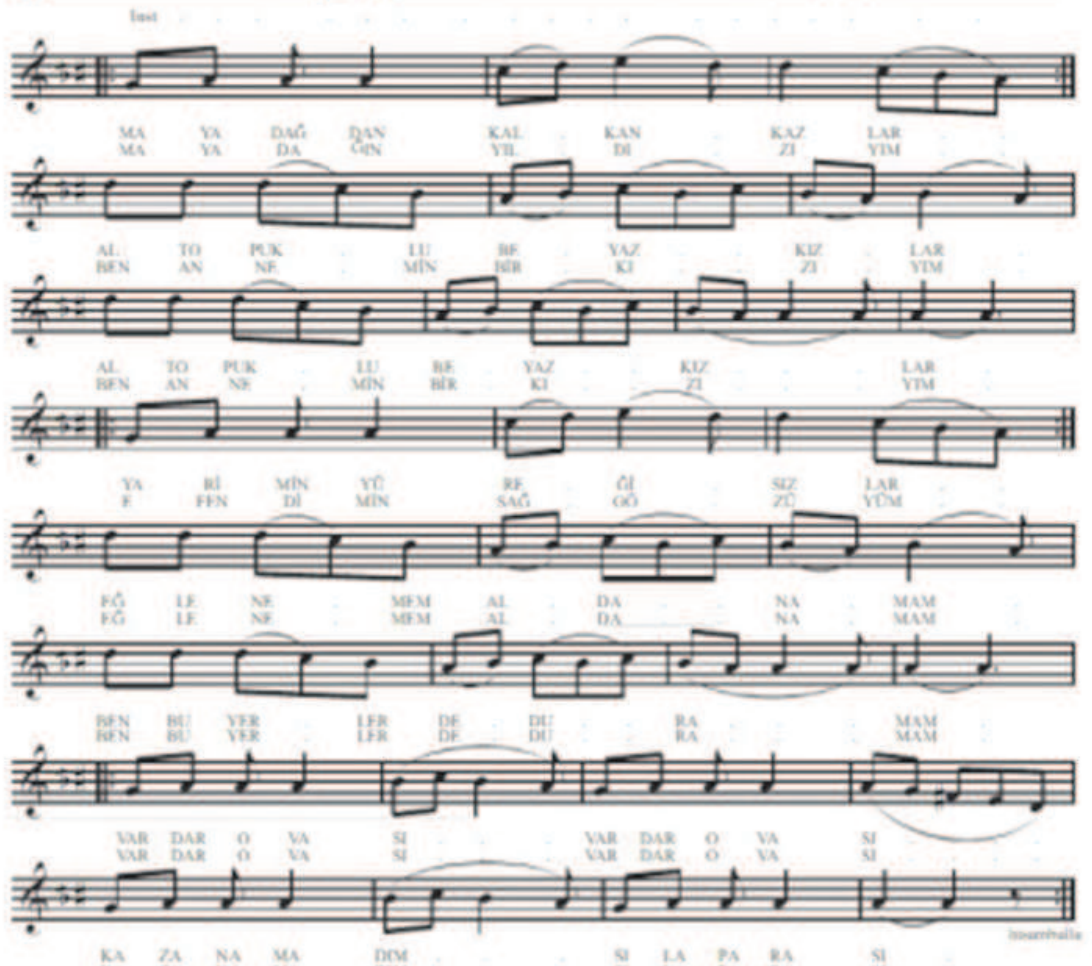

1

G WISADWNE MU:

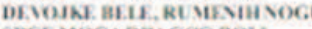

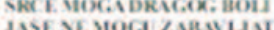

ANE WOG ON D. OSAT

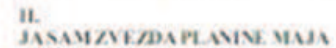

MDNKC MAK!

Di

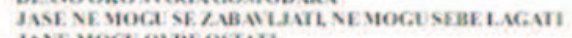

ANE Mocd ovDE OSWI 


\section{PЕЗЮМЕ}

Изучая культурную жизнь Сербии и Боснии и Герцеговины, каждый может увидеть влияние османской культуры в этом регионе. В течение пятого века османского владычества на Балканах турки проводили большую часть своего времени в городах, и их культура оказала влияние на формирование местных особенностей культурных и бытовых традиций. Восточное влияние заметно на национальные платья, особенно в городах, а также в стиле песен и танцев, где восточная мелисматика проявляется в использовании мелодий.

Ключевые слова: Сербия и Босния и Герцеговина, Балкан, восточная мелисматика, культура. 